\title{
CENTRIFUGAL RAW SUGAR
} (in 1,000 tonnes)

\begin{tabular}{|c|c|c|c|c|c|c|c|}
\hline Countries & $\begin{array}{l}\text { Average } \\
1979-81\end{array}$ & 1984 & 1985 & 1986 & 1987 & 1988 & 1989 \\
\hline Argentina & $\begin{array}{r}1,584 \\
1,581\end{array}$ & $\begin{array}{l}1,545 \\
1,545\end{array}$ & 1,174 & $1,120^{*}$ & 1,063 & $1,150^{*}$ & $\begin{array}{l}1909 \\
915^{*}\end{array}$ \\
\hline Australia 1 & 3,243 & 3,548 & 3,379 & 3,371 & 3,440 & $3,580^{*}$ & 3,679 \\
\hline Barbados 2 & 113 & 100 & 100 & 111 & 83 & $83 *$ & $66 *$ \\
\hline Brazil & 7,991 & $9,332 *$ & $8,274 *$ & $8,649 *$ & $8,458^{*}$ & $8,500 *$ & $7,409 *$ \\
\hline Canada & 118 & 113 & 54 & 122 & $147 *$ & $109 *$ & $135 *$ \\
\hline China & 3,809 & $5,352 *$ & $6,347 *$ & $6,340 *$ & $5,219 *$ & $5,925 *$ & $5,634 *$ \\
\hline Colombia & 1,192 & 1,178 & 1,367 & 1,297 & 1,390 & 1,415 & 1,425 \\
\hline Cuba & 7,510 & $8,331 *$ & $8,101^{*}$ & 7,467 & 7,232 & $7,548^{*}$ & $8,188^{*}$ \\
\hline Czechoslovakia & 808 & $844 *$ & $939 *$ & 862 & 818 & 614 & $755^{*}$ \\
\hline Dominican Rep. & 1,142 & 1,156 & 921 & 895 & 866 & $800 *$ & $810^{*}$ \\
\hline Egypt & 666 & 780 & $887 *$ & 959 & 1,007 & $1,029^{*}$ & 977* \\
\hline France & 4,720 & 4,305 & 4,324 & $3,734 *$ & $3,973 *$ & $4,424 *$ & $4,130 *$ \\
\hline Fiji I & 446 & 480 & 341 & 502 & 401 & 420 & $385^{*}$ \\
\hline German Demo.Rep. & 675 & $778 *$ & $798 *$ & $790^{*}$ & $760 *$ & $445^{*}$ & $668 *$ \\
\hline Germany, Fed.Rep.c & 3,261 & 3,151 & 3,454 & 3,479 & $2,963^{*}$ & 3,130 & 3,109 \\
\hline Guyana & 294 & 238 & 265 & 249 & $234 *$ & $168 *$ & $166^{*}$ \\
\hline India ${ }^{3}$ & 5,380 & 6,430 & 6,650 & 7,051 & 8,533 & 9,100 & $10,200 *$ \\
\hline Indonesia 4 & 1,286 & 1,500 & 1,767 & 2,013 & 2,073 & $1,800^{*}$ & 1,817 \\
\hline Italy & 1,956 & $1,385^{*}$ & $1,352 *$ & $1,868^{*}$ & $1,867 *$ & $1,607 *$ & $1,800^{*}$ \\
\hline Jamaica & 238 & 193 & 225 & 206 & $189 *$ & $221 *$ & $192 *$ \\
\hline Mauritius & 615 & 610 & 684 & 707 & 694 & 634 & 568 \\
\hline Mexico & 2,796 & $3,297^{*}$ & $3,489 *$ & $4,031 *$ & $3,986 *$ & $3,822 *$ & $3,678^{*}$ \\
\hline Pakistan ${ }^{3}$ & 734 & 1,258 & 1,430 & 1,210 & 1,364 & 1,936 & $2,011 *$ \\
\hline Peru & 571 & $620 *$ & $757 *$ & 599 & $560 *$ & $565^{*}$ & $580 *$ \\
\hline Philippines & 2,289 & 2,335 & 1,718 & 1,447 & 1,337 & 1,369 & $1,590 *$ \\
\hline Pola & 1,530 & 1,878 & 1,811 & 1,891 & 1,823 & $1,824 *$ & 1,850 \\
\hline Puerto Rico & 156 & 87 & 98 & 87 & 87 & 93 & $83^{*}$ \\
\hline S. A & 2,011 & 2,560 & 2,280 & $2,248 *$ & $2,235^{*}$ & $2,260^{*}$ & $2,276^{*}$ \\
\hline Spai & 934 & 1,166 & 976 & 1,111 & 1,108 & $1,088 *$ & $1,038^{*}$ \\
\hline & 350 & 392 & 346 & 386 & 275 & $396 *$ & $422 *$ \\
\hline Tha & 1,534 & $2,350 *$ & 2,572 & 2,586 & 2,637 & 2,705 & $4,052 *$ \\
\hline Trinidad & 117 & 70 & 81 & 07 & 85 & $91^{*}$ & $97 *$ \\
\hline Turkey & 1,178 & $1,655^{*}$ & $1,398^{*}$ & $1,414 *$ & $1,784^{*}$ & $1,595^{*}$ & $1,314 *$ \\
\hline USSR & 7,017 & $8,685^{*}$ & $8,260^{*}$ & $8,700^{*}$ & $9,565^{*}$ & $9,240 *$ & $9,565^{*}$ \\
\hline UK & 1,215 & 1,400 & 1,317 & 1,433 & $1,335^{*}$ & $1,413 *$ & 1,304 \\
\hline USA & 5,345 & 5,363 & 5,473 & 6,075 & 6,651 & 6,260 & 6,464 \\
\hline \multirow[t]{2}{*}{ World total } & 88,622 & 99,976 & 99,283 & 101,273 & 101,781 & 102,779 & 105,639 \\
\hline & tuel. & 8 & & & & & \\
\hline
\end{tabular}

